Classification

Physics Abstracts

01.70.+w - 02.90.+p - 61.72.Mm - 81.10.-h - 83.70.Fn

\title{
The Concepts of Grain and Aggregate Applied to the Mineral World
}

\author{
Jacques Y. Grolier \\ Université d'Orléans, BP 6759, 45067 Orléans Cedex 02, France
}

\begin{abstract}
Résumé. - Depuis toujours, la notion de grain est primordiale pour la compréhension du monde minéral. Bien qu'elle ait ses limites, elle continue d'inspirer les observateurs dans leur recherche de modèles appropriés à l'étude des minéraux et des roches. La stéréologie des formes est particulièrement importante, en raison de la signification génétique qui s'attache à la forme des minéraux. La modélisation des roches, même les plus simples (polycristaux monophasés), est subordonnée à l'état des connaissances sur la géométrie des polyèdres. On évoque dans cet article quelques avancées récentes en ce domaine. Une liste de sites proposant des images de minéraux et de roches sur le réseau mondial $(W e b)$ se trouve en annexe.
\end{abstract}

\begin{abstract}
From a long time, grain models were - and still they are - performing tools for studying the mineral and material world. Although their possibilities are in fact bounded, they are commonly used by observers of minerals and rocks. Specially important is the stereology of grain shapes, because shape generally has some genetic meanings. The effective modelling of rocks, even the simplest of them (i.e. monophased polycrystals) depends on the general results and progress in the geometry of polyhedra. Recent advances in this field are mentionned in this paper. A list of web sites where minerals and rocks can be viewed is given as an Annexe.
\end{abstract}

Tel est le monde : grand et magnifique ; les choses nous plaisent parce qu'elles sont belles et incroyables; tel est le monde pour un oeil naï qui n'y cherche que des images. Quel film! quelles couleurs; quelle technique ... $\left({ }^{1}\right)$.

Alexandre Vialatte

For the amateur as much as for the scientist, the mineral world is an astonishing sight by the multiplicity of the shapes and colours. This often occurs in Nature, and everywhere human activity is exerted on the underground: public works sites, quarries, mines, etc. Many museums, specially the main collections of mineralogy throughout the world, display a lot of minerals and rocks whose spectacular aspects are more or less explained through a number of convergent sciences (physical

$\left({ }^{1}\right)$ Such is the world: great and wonderful; things are pleasant because they are beautiful and incredible; such is the world for a naïve eye. What a movie! What colours; what a technique ... 
chemistry, cristallography, mineralogy, geochemistry, petrology). Several images and geometrical models are inspired by daily life sometimes from ancient times and play there the main role.

The purpose of this short paper is a modest and concrete one: to show, with the example of grain model and images derived from it, how a very simple and fundamental concept, deep-rooted within one's and every people's history has been playing a prominent part, within scientific research and how it is still an aid for understanding the world, here the mineral world. It should be noted en passant that the geologists interested in quantitative petrography would derive advantages in keeping themselves well informed in the progress of metal and other material sciences; for example a polycrystal is a polycrystal whatever the forming phases are. They would also derive advantages in participating in the present progress of physics of soft or weakly coherent granular media. The mineral world gives many examples of such media, the most familiar one being sand.

To-day where can we find images (raw images or schematic representations) of crystalline structures, minerals and rocks? Of course within the textbooks of mineralogy, for instance [1], the good popular treatises [2,3], the atlas of petrography [4-7] and the manuals of ore microscopy [8]. Recently, and this is an interesting evolution indeed, they can also be found on the World Wide Web; thanks to some great institutions [W1, W2, W5], scientific associations [W3, W4], mineral shops [W6] and/or lodging other image sites [W7] or even from individual people [W7, W8, W9]. So, everybody is now able to go for a cheap mineralogic walk to the great and small world collections (the main sites refer the ones to the others and a way to search images of minerals is, besides the usual procedures well known by any cybernaute, to begin with the site of the École des Mines de Paris [W1] or with the Spanish site [W3] or the Amsterdam Museum [W10], or the one given in reference [W11]).

"Nice crystals" have always drawn the attention of the scientists as well as of the public; "nice crystals", i.e. with large and well developed faces. Moreover, among the quality criteria of a specimen are the limpidity, the global size of the object, the singularity or on the opposite the exemplary features of the shapes and colours. The relative value of all these criteria is balanced by each person in charge of a mineralogical data base of images. In this field, the criteria of selection seem to be rather subjective. As an example, the image data base of the Collection de Minéralogie de l'École des Mines de Paris [W1] allows to look for minerals according to the quality of specimens is namely exceptional, excellent, very good; each of these classes being split in case the object is very pure or very large $\left(^{2}\right)$

To date (Sept. 1996), although it would be very useful, it looks as if no mineralogical data base has been organized yet for carrying out research according to the habitus of minerals; i.e. the external look, of which the main part is the shape. The shape of crystals is indeed fascinating to many minds. Sometimes the painter finds his inspiration for exciting works of art $\left({ }^{3}\right)$ and so does the architect $\left({ }^{4}\right)$. But first of all, and that is interesting for the scientist, shape has some structural and genetic meanings. Where structure is concerned, the historic role of observation for the pioneers in cristallography is famous. About genetic meaning, a now classic example is zircon [11].

The influence of the environment and of the conditions of crystallization upon crystal shapes appears all the more striking if the crystals of a same mineral species are compared: 1) with few crystals developed in an homogeneous fluid (homogeneous or homogeneous-like as far as the matter exchanges required for the crystal growth are concerned); 2) with a lot of crystals, so numerous

\footnotetext{
$\left({ }^{2}\right)$ This scale of quality is due to Guillemin $[9,10]$. To-day one can foresee how by using the techniques of image analysis and comparing ideal shapes and real shapes, some parameters taken into account in such a scale could be quantified.

$\left({ }^{3}\right)$ So the superb quartz, hexagonal prism shaped with bipyramid, represented by painter W. Siudmak, for the Cristaux Géants exhibition, open in 1983 at the Muséum National d'Histoire Naturelle, Paris.

$\left({ }^{4}\right)$ See for example the pavillon du Kinemax at the Futuroscope, Jaunay-Clan, near Poitiers, France. This surprizing building is represented in [W12].
} 


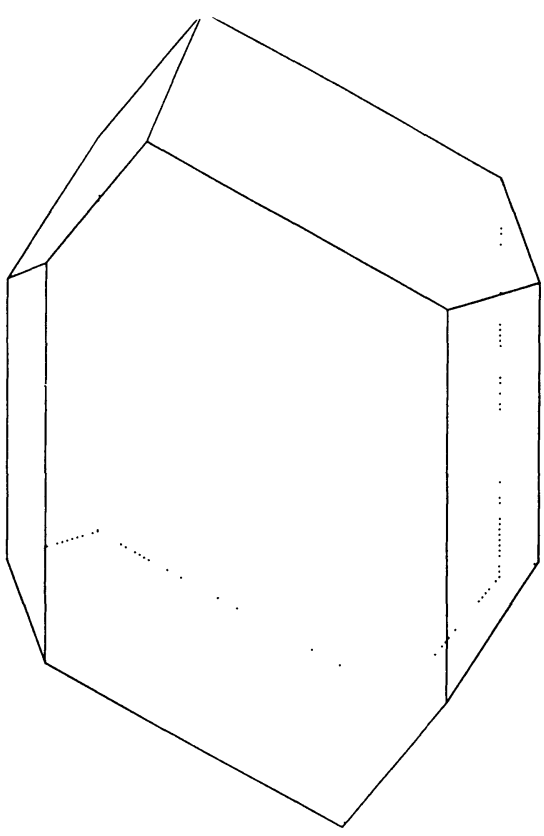

Fig. 1.

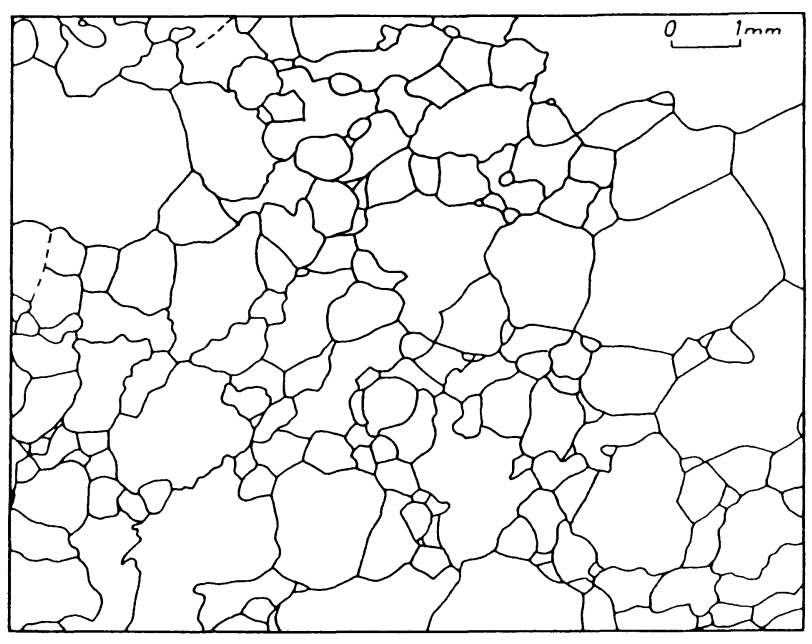

Fig. 2.

Fig. 1. - Ideal shape of a monocrystal of plagioclase (drawing by J.-M. Le Cléac'h).

Fig. 2. - Section of the intergranular net of an anorthosite, Egersund, Norway (from [15], Fig. 1). The shape represented Figure 1 is of course of no aid for the stereologic analysis of such an image.

that their growth is impeded, and submitted to many concomitant influences (reactions between neighbouring mineral phases, exchanges of matter between crystal and nearby liquid, recrystallization, strain, etc.). The usual shape (Fig. 1) of an isolated crystal of plagioclase of medium composition (andesine-labrador) has nothing in common with that of the same mineral in a polycrystalline aggregate such anorthosite (Fig. 2), a monomineralic rock with the same composition as the monocrystal. Neither is there anything in common between the ideal shape of an isolated peridot, such as the one represented in [3, p. 33] and the grain shape of peridot from peridotites.

In the same way, it is worth comparing the images of the nice quartz crystals of La Gardette, Isère ([W1], specimens $\langle 15918\rangle,\langle 1711\rangle,\langle 1732\rangle ;[\mathrm{W} 8], \ldots /$ rocks/lagardettfr.htm) and those of quartz as it can be viewed in thin sections of many rocks ([4-6], [W13]). More subtle and with a controversial meaning is the difference between idioblastic garnets and xenoblastic garnets within a same class of rocks, the metamorphic one [W14].

\section{The Grain Concept}

The word grain comes from the latin granum (grain). It means "any fruit or seed measuring only a small volume: corn grain, grape, peppercorn, etc." (translated from [12]); or again, and here the semantic link is more explicit, "Fruit and seed from some plants, [particularly] pods ... [and] by shape analogy or by quantity analogy, 1) small body, round or prolate shaped;2) tiny part of something ..." (translated from [13]); from that are derived grain of sand, grain of salt (in proper and 
figurative senses), goldgrains (translated from [13], p. 397) and the usual geologic terms, granite, granulite, granulometry, garnet, granular and, may be less common for the geologist (see hereafter), grain boundary $\left({ }^{5}\right)$.

So, going from botany to petrology, one ought to use the term grain only to mention small rock elements, let us say smaller than $1 \mathrm{~cm}$ or $1 / 2 \mathrm{~cm}$. Of course grain is inadequate on principle to describe the megacrystals in porphyroïd texture rocks, the crystals of the pegmatites and other big objects such as the orbicules of some magmatitic rocks. A grain is neither a pellet nor a ball! However it should be noted that minerals and rocks do not easily fit in perfectly cut classes ...

\section{The Concept of Grain Boundary}

If several grains are in contact, the contact surface or the thin domain of the transition from one grain to another is called grain boundary. More precisely, following the usage of material science, the grain boundary corresponds to the case where the grains in contact are of the same phase; the general case (crystal contact without any other mention) is referred by the word interface. So, saying that a rock is a monomineralic one is equivalent to saying that it is a monophased polycrystalline edifice. A recent and general monography about interfaces was written by Sutton and Baluffi [14]. In the special context of rocks, this subject is discussed in [15] and ([16], chap. 10).

\section{The Shape and Size of Grains}

For the sedimentologist, the shapes and sizes of grains are important features to describe, because they are of valuable help to identify the strata and to recognize their conditions of formation. When they are soft rocks (e.g. sand) the usual techniques are granulometric analysis by sieving (study of size distribution), and lens observation or simple visual comparison for the study of shapes. In these fields, image analysis offers a set of complementary or concurrent techniques [17]. Moreover, it has the noticeable advantage of working with solid rocks.

Most magmatic and metamorphic rocks are solid rocks. Hence, the methods of image analysis and of stereology are practically the only ones that can be used for studying the sizes and shapes of grains from such rocks. The general aspects of these questions are dealt with in [18-20] and, for the special context of quantitative petrography, in [16]. A recent methodological work [21] presents in a concrete case - the one of a granite - some methods for acquiring the images, with their respective advantages, and shows how the image processing allows to modelize the distributions of sizes of shape and of orientation of the minerals.

Let us restrict now the subject to the mineral shapes in rocks. We have previously mentioned with the examples of plagioclases, peridots, quartz and garnets how a given mineral species can take either the shape of polyhedral crystals (idioblastic, idiomorphic, automorphic - these terms are synonymous) or bad-facetted crystals, i.e. with sinuous contours when observed in thin sections. If we now compare the different minerals from this point of view, it would seem that some species have, more than some others, a particular aptitude to develop in polyhedral forms. But the fact, based on a lot of observations, that it is possible to classify the minerals according to their tendency to idiomorphism (see f.e. [15], Tab. I) should not lead anyone to dream. There is no simple explanation to look for. The existence of such an idiomorphism scale probably results from a combination of multiple influences; with at least two extreme genetic types: on one hand, free growth producing well individualized polyhedral crystals, owing their shape mainly to the crystalline structure of the mineral species considered; on the other hand, the antagonistic growth which produces crystals whose the shape is essentially due to space filling. In the latter

\footnotetext{
$\left({ }^{5}\right)$ In addition, the word grain appears in the good French translation of "graded bedding": granoclassement.
} 
Table I. - Number $N$ of 3-valent polyhedra having $n$ faces (triangular or not) and number $N^{\prime}$ of polyhdera without triangular faces.

\begin{tabular}{|c|c|c|c|c|c|c|c|c|c|c|c|}
\hline$n$ & 4 & 5 & 6 & 7 & 8 & 9 & 10 & 11 & 12 & 13 & 14 \\
\hline$N$ & 1 & 1 & 2 & 5 & 14 & 50 & 233 & 1249 & 7595 & 49041 & $?$ \\
\hline$N^{\prime}$ & 0 & 0 & 1 & 1 & 2 & 5 & 11 & 34 & 130 & 525 & 2472 \\
\hline
\end{tabular}

case the shape problem comes down to sterical hindrance. For more details, the reader will refer to ([16], chap. 5-6-7) and [22].

Let us simply recall - a result often derived - that the mean number of faces of a grain in a compact aggregate filling the space without lacune nor overlapping and considered at the equilibrium is near of 13.4. That is to say, since this number in not an integer, it is impossible to correctly modelize such an aggregate assembling tetrakaïdecahedra (polyhedra with fourteen faces), whether they should be identical ones $[23,24]$ or different the ones from the others $[25,26]$.

Moreover, one could in theory build quite correct models of aggregates with the ideal mean number of faces and there are many ways to do that: assembling several types of polyhedra types, with thirteen faces, with a bit less than thirteen faces and a bit less than fourteen faces, etc. There is the choice ... At present, all the topologic types of polyhedra including polyhedra with thirteen faces, these faces being triangular or not, are known. The inventory, drawn up by different authors especially [27], of the polyhedra having at most eleven faces is given Table I, from [28].

The number of polyhedra having twelve faces, including the case where some faces are triangular, is 7 595; this result first obtained by Bowen and Fisk, quoted by Grace [29] is corroborated by the works of Hucher and Sabatier (private communication). And the total number of polyhedra having thirteen faces is 49041 ; this new result, yet unpublished, recently obtained by Hucher and Sabatier is announced here with their kind permission. Two concordant methods were used: computer programmation and manual sections systematically upon all the topologic graphs from the tetrahedron. With the thirteen faces polyhedra, the manual method is probably reaching the ultimate limit of what can be humanely done, because the number of polyhedra is growing fast with the number of faces. So, if there is some works remaining to do in that direction, at least the methods for programming this problem are now known (Sabatier). Extrapolating the values mentionned Table I, one can expect to find a total number (of topologic graphs) of tetrakaïdecahedra of about 200000.

But, assuming that the forms having triangular faces are, if not missing in the natural compact aggregates, at least unnecessary for modelling, one can restrict the choice to the polyhedra without triangle. And if one does not claim to get all the possible combinations, but only a unique model of aggregate with fifteen to sixteen faces and exactly 13396 faces mean per grain, the goal is probably accessible, without too much effort (but not proved! ...). Indeed the topologic graphs of all the polyhedra having up to fourteen non triangular faces are known ([27, 28] and here Tab. I). We previously presented [25] fifty nine models of tetrakaïdecahedra among which anybody can make their choice. Finally, there is no difficulty to obtain several graphs of pentakaï- and hexakaïdecahedra, either by troncature of a tetrakaïdecahedron followed by a Williams transformation [24], either directly via a Williams transformation of an already known polyhedron having fifteen or sixteen faces (such polyhedra are well described in the studies about the clathrates ([30], Figs. 2, 3]).

Recent works ([31] and quoted references) about polycrystalline aluminium reveal some correlations between the types of grain boundary, the size and the shape of the grains. No doubt 
that similar researches about monophased rocks would help to a better understanding of the mineral shapes within all kinds of rocks.

\section{Discussion and Conclusion}

Between the two extreme cases of the free and the antagonistic crystal growths and depending on the mechanical and geochemical conditions of survival of the mineral phases, there is a huge variety of intermediate situations and processes leading to the most frequently observed structures in the rocks: a large field indeed to be investigate in quantitative petrography. There the grain archetype keeps on all its usefulness, to describe the shapes of minerals, to compare them and finally, taking into account the results of experimental mineralogy and the general laws of crystallogenesis, to reveal their raison d'être. Certainly there will be a need to specify some characteristics of the tool to make it more efficient in practice, say for example according which criteria there are grains or subgrains; consider that a mineral grain is not only a small object, but that is also and fundamentally a convex; or - question of definition - distinguish convex and non-convex grains, since neither could be processed the same way in the stereological analysis.

Of course, the mineral world is not only a set of grains. A number of observed structures (symplectic, graphic, pegmatitic, coronitic, dendritic, and others, as also the complex and anastomozed structures of the montmorillonitic clays) justify other models, some of them already known (fractals) or remaining to be imagined.

\section{Acknowledgements}

A. Astruc, J. Fabriès, M. Hucher, J.-M. Le Cléac'h, J. Riss, G. Sabatier, M. Vidal gave generously their help during the preparation of this paper. It is a pleasure to thank all of them.

\section{Appendix}

\section{Electronic Image references on the Web}

[W1] Collection de minéralogie de l'École des Mines de Paris:

http://cri.ensmp.fr/mineral

[W2] Collection by Dr. Schuster, Techn. Univ. Clausthal:

http://www.immr.tu-clausthal.de/labs/mincoll

[W3] Some images of minerals from Spain on the site:

http://155.210.170.2/otros/miner/mineralfr.html

[W4] Minerals from Norway at:

http://www.uio.no:80/ hansjb/pic.html

[W5] Some minerals from Switzerland at the Bern Museum:

http://nmbe0.unibe.ch/

[W6] http://rockhounds.com/rockshop/

[W7] http://rockhounds.com/rockshop/minimage.html

[W8] http://www.novagate.com/ ahines/rocks/indices.html

[W9] http://math.berkeley.edu/ smale/crystal.html

[W10] http://www.xs4all.nl/ mineral/

[W11] http://www.earth.ox.ac.uk/ daveWa/minerals.html

[W12] http://www-syntim.inria.fr/syntim/Futuroscope/KinemaxWWW.html and, small:

http://......../Futuroscope/KinemaxFFF.html 
[W13] Minerals in Thin Section Database (Univ. of British Columbia):

http://www.science.ubc.ca/ geol202/s/cgi-bin/mineral.cgi

[W14] id.: ..../ geol202/s/meta/porphyroblast.html

\section{References}

The short text by Alexandre Vialatte put in exergue is from one of the Chroniques des plaisirs de l'homme, in "L'éléphant est irréfutable" (Juillard, Paris, 1980) p. 43.

[1] Deer W.A., Howie R.A. and Zussman J., Rock forming minerals, vol. 1-5 (John Wiley, New York, 19621963).

[2] Minéraux. Collection de Documents d'histoire naturelle (Société Française du Livre, Paris, 1968) 162 planches d'artiste par C. Caspari, direction scientifique H. Schröcke et K.L. Weiner, adaptation française J. Wyart.

[3] Monde \& Minéraux, numéro spécial Musée de Minéralogie (École des Mines de Paris, nov.-déc. 1984) $n^{\circ} 64$.

[4] MacKenzie W.S. and Guilford C., Atlas de pétrographie. Minéraux de roches observées en lame mince, traduit de l'anglais par J.-P.Michel (Masson, Paris, 1993).

[5] Adams A.E., MacKenzie W.S. and Guilford C., Atlas des roches sédimentaires, traduit de l'anglais par J.-P. Michel (Masson, Paris, 1995).

[6] MacKenzie W.S., Donaldson C.H. and Guilford C., Atlas des roches magmatiques, traduit de l'anglais par J.-P. Michel (Masson, Paris, 1995).

[7] Yardley B.W.D., MacKenzie W.S. and Guilford C., Atlas des roches métamorphiques, traduit de l'anglais par J.-P. Michel (Masson, Paris, 1995).

[8] Craig J.R. and Vaughan D.J., Ore Microscopy and Ore Petrography (John Wiley, New York, 1981).

[9] Guillemin C., En visitant les grandes collections minéralogiques mondiales (BRGM éd., 1964).

[10] Guillemin C., id. (BRGM éd., complément à la publication de 1964, 1972).

[11] Pupin J.P. and Turco G., Bull. Minéral. 104 (1981) 724-731.

[12] Nouveau Petit Larousse illustré, Quatre cent vingt-troisième édition, 1947.

[13] Trésor de la langue française. dictionnaire de la langue du XIXe et du XXe siècle (Éd. du C.N.R.S., Paris, Tome neuvième, 1981) p. 396-397.

[14] Sutton A.P. and Balluffi R.W., Interfaces in Crystalline Materials (Oxford Univ. Press, Monographs on the Physics and Chemistry of Materials $\left.n^{\circ} 51,1995\right)$.

[15] Grolier J., Colloque CNRS Les joints intergranulaires dans les métaux, St-Etienne, 16-20 juin 1975. J. Phys. Colloq. France 36 (1975) C4-427-439.

[16] Grolier J., Fernandez A., Hucher M. and Riss J., Les propriétés physiques des roches. Théories et modèles (Masson, Paris, 1990).

[17] Bonardi M. and Tosi L., Eur. Microsc. Anal. 35 (1995) 17.

[18] Serra J., Image Analysis and Mathematical Morphology (Academic Press, London, 1982).

[19] Coster M. and Chermant J.L., Précis d'analyse d'images (Éd. du C.N.R.S., Paris, 1985).

[20] Cocquerez J.-P. and Philipp S. (coord.), Analyse d'images: filtrage et segmentation (Masson, Paris, 1995).

[21] Wu J., Description quantitative et modélisation de la texture d'un granite: granite de Guéret (France), Thèse de doctorat de l' Université Bordeaux I, géologie appliquée (1995).

[22] Riss J., Principes de stéréologie des formes en pétrographie quantitative. Thèse de doctorat-ès- Sciences, Orléans (1988).

[23] Thomson W., Philos. Mag. and J. Sci. XXIV, 5 (1887) 503. 
[24] Williams R.E., Science 161 (1958) 276.

[25] Hucher M. and Grolier J., J. Microsc. III 3 (1977) 329.

[26] Grolier J. and Hucher J., C.R. Acad. Sc. Paris 286 n $^{\circ}$ D (1978) 177.

[27] Hucher M., Sabatier G. and Grolier J., Discrete Appl. Math. 2 (1980) 255.

[28] Hucher M. and Grolier J., Présentation d'un catalogue de polyèdres. SGF-ISS, 15th meeting of the French ISS Group, 8 Feb. 1991.

[29] Grace D.W., Computer Research for non isomorphic convex poyhedra, Ph. D., Technical Report CS15, Stanford University, Ca. (1965).

[30] Allen K.W., J. Chem. Phys. 41 (1964) 840.

[31] Garbacz A., Ralph B. and Kurzydłlowski K.J., Acta Stereol. 14/1 (1995) 61. 